\section{PRIMEROS APUNTES SOBRE LA QUINTA DA REGALEIRA DE LUIGI MANINI: EL PALACIO (1893-1912)}

\author{
Iván Moure Pazos \\ Università di Bologna \\ Universidade de Lisboa \\ Universidade de Santiago de Compostela \\ ivan.menes@yahoo.es
}

Cómo citar este artículo/Citation: Moure, I. (2016). "Primeros apuntes sobre la Quinta da Regaleira de Luigi Manini: el Palacio (1893-1912)". Arbor, 192 (777): a295. doi: http:// dx.doi.org/10.3989/arbor.2016.777n1011

Recibido: 16 julio 2014. Aceptado: 24 noviembre 2015.

RESUMEN: El presente artículo pretende ser un "fresco" de los principales diseños arquitectónicos propuestos para la construcción del Palacio de la Quinta da Regaleira en Sintra, analizando cuáles fueron los factores condicionantes que configuraron el desarrollo del actual complejo edilicio. Asimismo, se persigue dar respuesta a reincidentes demandas, de tipo interpretativo, que afloran en la literatura crítica lussoniana y maniniana. ¿Por qué se frustra el primer proyecto de Lusseau para el Palacio de la Quinta da Regaleira? ¿Cómo un arquitecto italiano, a priori ajeno a la cultura neomanuelina, "gótica" y "flamígera", pudo haberse convertido en la figura más aclamada del neomanuelino Portugués?

PALABRAS CLAVE: Quinta da Regaleira; Henri Lusseau; Luigi Manini; Sintra; Neomanuelino.

\section{FIRST NOTES ON LUIGI MANINI'S QUINTA DA REGALEIRA: THE PALACE (1893- 1912)}

Copyright: (C) 2016 CSIC. Este es un artículo de acceso abierto distribuido bajo los términos de la licencia Creative Commons Attribution-Non Commercial (by-nc) Spain 3.0.
ABSTRACT: This paper deals with the main architectonic designs proposed for the construction of Quinta da Regaleira Palace at Sintra, analysing the factors that determined how the building complex we can see today developed. It also seeks to address questions of interpretation that frequently arise in the critical literature concerning Lusseau and Manini. Why were Lusseau's first plans for the Quinta da Regaleira Palace frustrated? How was an Italian architect who was, a priori, alien to NeoManueline culture, and "gothic" and "flamboyant" styles, able to become the most acclaimed figure of the Portuguese NeoManueline style?

KEYWORDS: Quinta da Regaleira; Henri Lusseau; Luigi Manini; Sintra; Neo-Manueline. 


\section{INTRODUCCIÓN}

Con motivo del octogésimo aniversario de la muerte de Luigi Manini (1848-1936), creemos pertinente el análisis de una de sus obras más aclamadas, el Palacio para la Quinta da Regaleira (1893-1912) en Sintra. Manini realiza para el apoderado Carvalho Monteiro (1848-1920) una "obra de arte total", de difícil abordaje en un artículo de estas dimensiones, por lo que consideramos oportuno centrar nuestro esfuerzo en el estudio específico del Palacio principal, que preside el inabarcable complejo, "salpicado" de innúmeras macro y microarquitecturas firmadas por el genio cremonese: grutas subterráneas, acuarios, fuentes... ${ }^{1}$.

Inicialmente, y como veremos en el primer epígrafe del artículo, Carvalho Monteiro encomienda al afamado arquitecto y paisajista galo Henri Lusseau (s. f), la construcción del enorme complejo en la sierra de Sintra. La fallida propuesta de Lusseau, en estilo "segundo imperio" francés, resulta, entre otras cosas, excesivamente académica para el filántropo brasileiro, frustrándose la materialización de este primer proyecto inicial. Forzosamente, Monteiro se ve obligado a buscar otro proyectista para su Quinta, encomendando la nueva dirección del complejo a Manini. En este primer proyecto, también frustrado, Manini pondrá en énfasis tanto sus primeros conocimientos escenográficos como sus previas aportaciones arquitectónicas en el monumental complejo hotelero de Buçaco (1888-1907) en Coimbra. Problemas con la adquisición de terrenos, obligan a redimensionar la primera propuesta de Manini, del todo excesiva en su planteamiento tectónico y estructural. El arquitecto solventa el problema adecuando la estructura del complejo a la nueva disposición del terreno. Haciendo gala de un inigualable dominio del lenguaje neomanuelino, -del todo extraña en un arquitecto de procedencia lombarda- reconduce el edificio hacia formas más livianas, incidiendo en una mayor desmaterialización de la superficie mural.

Lo que sigue, no sólo pretende poner en orden algunas "lagunas" histórico-artísticas del proceso constructivo del Palacio de la Quinta de la Regaleira, sino que, también, se persigue dar respuesta a reincidentes demandas, de tipo interpretativo, que afloran en la literatura crítica lussoniana y maniniana. ¿Por qué se frustra el primer proyecto de Lusseau para el Palacio de la Quinta da Regaleira? ¿Cómo es posible que un artista italiano, se convierta en el mayor referente internacional del neomanuelino portugués? ¿Cuáles fueron los factores condicionantes y facilitadores que favorecieron la creación del actual Palacio?
El primer proyecto de Henri Lusseau para el Palacio de la Quinta da Regaleira: una propuesta afrancesada

La documentación histórica sobre la Quinta da Regaleira previa al año 1893 es prácticamente inexistente, perdiéndose entre las diferentes compras y ventas que han caracterizado el complejo desde el siglo XVII hasta la actualidad. Se sabe que la designación actual, en origen, data de 1830, año en que el propietario, Manuel Bernardo Lopes Fernades (1797-1870), acuña su villa sintrense bajo rúbrica de Quinta da Regaleira, quedando relegada para siempre la antigua designación Quinta da Torre. En 1840 la Baronesa da Regaleira -Ermelinda Allen Monteiro de Almeida (1768-1858)-, hija de un rico comerciante de Oporto, adquiere la propiedad al viejo titular (Pereira y Luckhurst, 2006, p. 70) hasta que en 1893 el célebre apoderado y coleccionista brasileiro António Augusto Carvalho Monteiro compra -por la suma de veinticinco contos de reais- los terrenos de la villa y el palacio a los barones de la Regaleira, iniciándose así la actual historia del complejo (Pereira y Luckhurst, 2006, p. 71).

En 1895, -dos años después de la adquisición de la propiedad-, Carvalho Monteiro, encomienda al afamado paisajista y arquitecto francés Henri Lusseau los primeros proyectos para su palacio, jardín y cocheras (Luckhurst y Pereira, 2007, p. 91). Tal y como apostillan Gerald Luckhurst y Denise Pereira, "el 27 de Junio, Lusseau envió de París los primeros proyectos acuarelados para el palacio y el 31 de agosto firmó cuatro perspectivas para los jardines de la Regaleira" (Pereira y Luckhurst, 2006, p. 93). El próximo año, concretamente, el " 4 de enero, termina los diseños para las cocheras y en marzo de ese mismo año presenta las verdaderas propuestas de los cuatro alzados para el palacio" (Pereira y Luckhurst, 2006, p. 93) [Fig.1].

Fig. 1. Henri Lusseau. Primer proyecto para el Palacio de la Quinta da Regaleira: alzado. 1895. Sintra. Cámara Municipal. Archivo histórico.

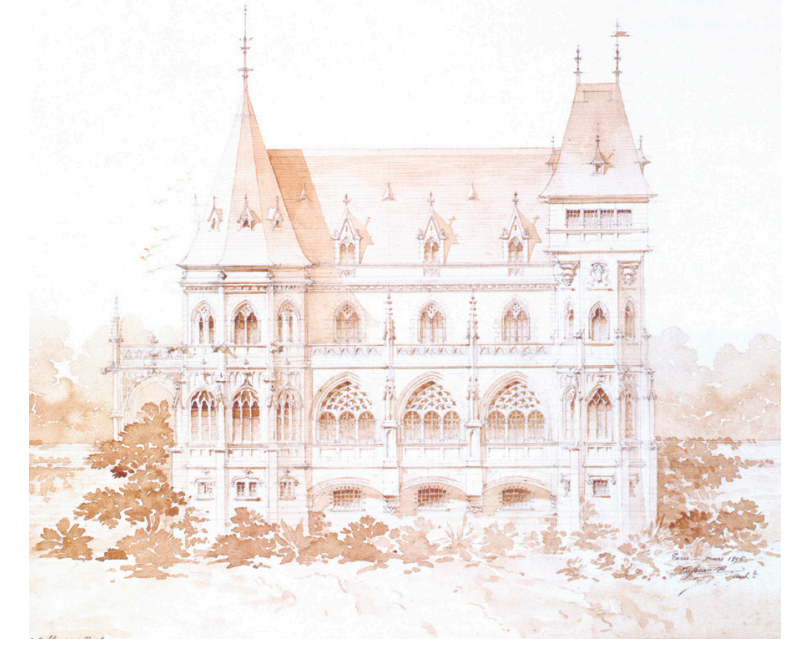


Pese a la elegancia del proyecto, Monteiro rechaza las propuestas que le llegan de París por parte de Lusseau. La idea comúnmente aceptada es que la interpretación historicista de este primer proyecto obedecía a un temperamento típicamente francés no grato a los gustos lusitanos de Monteiro (Moure, 2014, p. 112). Tal y como apunta Giovanna D’Amia: “[...] la gran fiesta del centenario de Luís Camões (1524-1580), había contribuido al renacer del patriotismo lusitano" (D'Amia, 2007, p. 59). Sin embargo, resulta inexplicable que, un artista de tal fama y versatilidad, no supiese interpretar las directrices propuestas por Monteiro. Ésto, hace pensar más en una falta de entendimiento entre los interesados, que en una clara limitación artística y proyectiva por parte del arquitecto y paisajista galo. Varios datos orientan hacia esta hipótesis. En 1891 -cuatro años antes del encargo de Carvalho Monteiro para la Regaleira-, Lusseau, diseña para la casa del industrial Conceição e Silva (s. f) un espectacular proyecto neomorisco en el corazón de Lisboa. [Fig. 2]. Se trataba del segundo proyecto encargado por Conceição e Silva, tras rechazar la propuesta inicial en estilo francés "segundo imperio" del arquitecto Domingos Parente da Silva (1836-1901), de extrañas concomitancias, con el diseño que Lusseau entrega a Monteiro (França, 1998, p. 20). [Fig. 3].

Fig. 2. Domingos Parente da Silva. Primer proyecto para el Palacio de Conceição Silva: alzado. 1888. Lisboa.

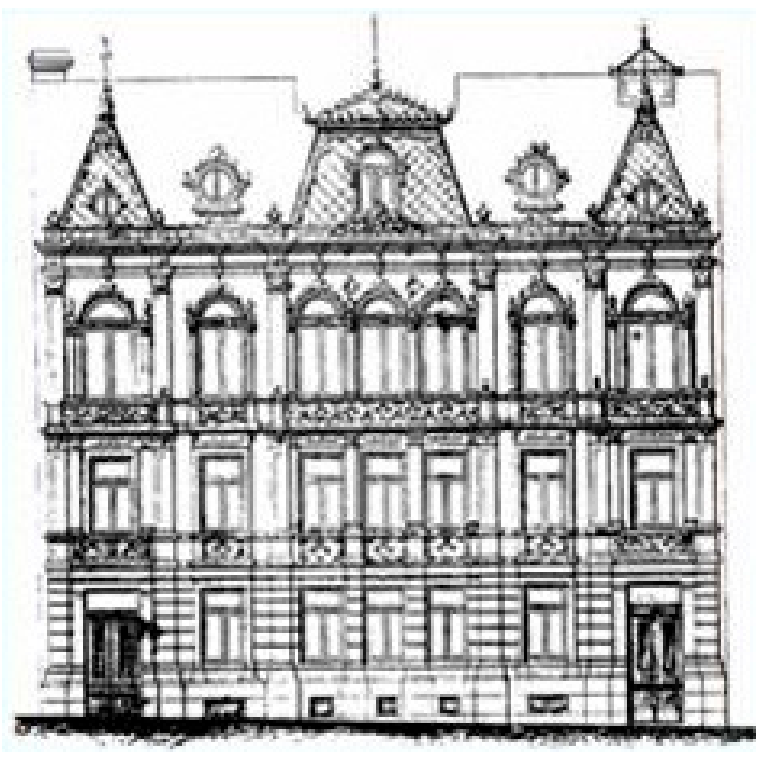

Fig. 3. Henri Lusseau. Proyecto para el Palacio de Conceição e Silva en Lisboa. 1891.

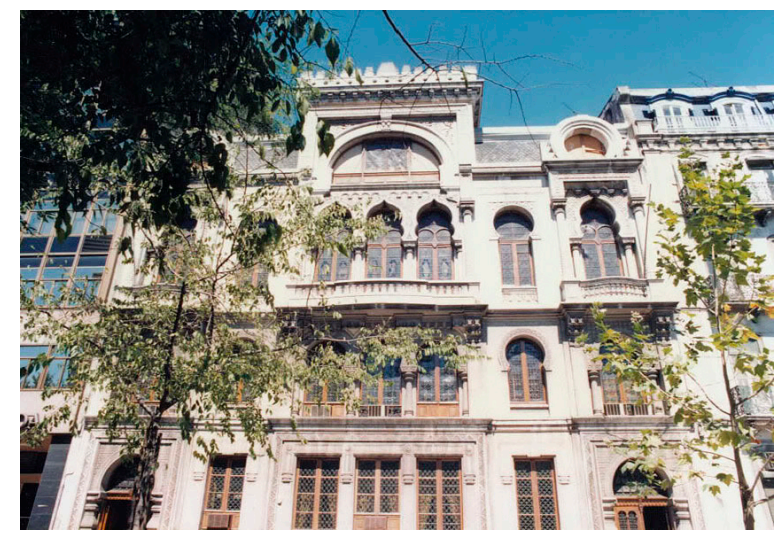

No deja de sorprender, que Lusseau ofreciese a Carvalho Monteiro una propuesta parisina cuando él mismo, resuelve magistralmente el excesivo clasicismo afrancesado de Parente, con una propuesta arriesgada y profundamente orientalista y morisca. Todo esto incide en la hipótesis de falta de entendimiento mutuo entre Carvalho Monteiro y Henri Lusseau; enfatizado, probablemente, por sus fuertes carácteres.

Sea como fuere, la infructuosa relación artística entre Monteiro y Lusseau, obliga al empresario a buscar nuevas propuestas para la construcción del gran pedernal.

Tras dos años de intensa búsqueda, finalmente, el 8 de agosto de 1898, Monteiro confía al arquitecto Luigi Manini la materialización de su gran proyecto vital, de corte, como veremos, profundamente escenográfico y neohistoricista (Luckhurst y Pereira, 2007, p. 92).

\section{PRIMER PROYECTO FRUSTRADO DE LUIGI MANINI PARA EL PALACIO DE LA QUINTA DA REGALEIRA: LA EXALTACIÓN ESCENOGRÁFICA}

Manini, alejándose de la propuesta más académica de Lusseau, opta por un proyecto exaltador del ánima lusitana de sabor puramente neomanuelino. Sin embargo, cabe apuntar que la sección horizontal del proyecto, en esencia estructural, no dista mucho del común academicismo francés del siglo XVIII. El complejo se articula en base a una planta cuadrada de marcada funcionalidad con cinco cuerpos sobresalientes y un ábside pentalateral en resalte, a los cuales se accede por una monumental escalinata principal. El interior se distribuye en base a dos ejes ortogonales sobre los cuales se disponen grandes salas, "evitando, por otro lado, largos corredores, normalmente sustituidos por atrios o vestíbulos que funcionan como núcleos de distribución" (Carita, 2006, p. 103). [Fig. 4]. 
Fig. 4. Luigi Manini. Primer proyecto frustrado para el Palacio de la Quinta da Regaleira: perspectiva de planta y piso noble. 1898. Crema. Museo Cívico de Crema y del Cremasco.

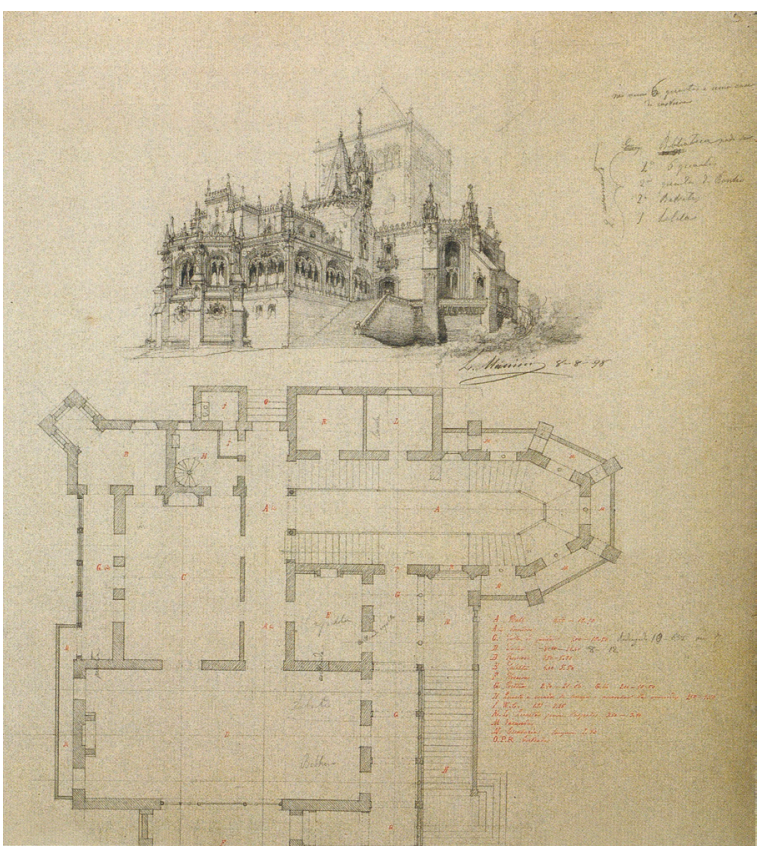

Se trata de una antigua y clásica tipificación edilicia, ya ensayada por Luigi Manini en el gran complejo hotelero de Buçaco, el cual, se aleja de las plantas de otras propuestas previamente proyectadas, como la "lombarda" Villa Sassetti (1890), erigida también en el corazón de la paradisíaca Sintra (Pereira y Luckhurst, 2004, pp. 253-280; Pereira y Luckhurst, 2008, pp. 200-210):

"lo cierto es que los arquitectos y teóricos neoclásicos ya habían aportado las resoluciones definitivas al modelo de estructuración ortogonal [...] el grueso de los autores decimonónicos van a seguir inspirándose en la mismas fuentes y tratados que otrora configurasen el advenimiento neoclásico" (Moure, 2011, p. 260).

El alzado se articula en varios volúmenes superpuestos sobresaliendo un gran elemento torreado en cuatro aguas, puesto en relación por Helder Carita con la Torre dos Brasões del Palacio Real de Sintra (1508) (Carita, 2006, p. 101). La planta noble se aligera con una enorme logia que desmaterializa la superficie mural, inspirada, tanto en su anterior proyecto de Buçaco (Luckhurst y Pereira, 2004, pp. 51-63) (Denby, 1998, p. 248), como en el Claustro del Monasterio de los Jerónimos de Lisboa (1514) (Carita, 2006, p. 101). [Figs. 5-6]. En cuanto al ábside pentalateral, podríamos afirmar, que no es más que una bonita "iglesia gótica", vinculada, como veremos posteriormente, tanto a su obra previa para escenografía como a las "plantillas constructivas" de Domenico Moglia (1780-1863) y Violletle-Duc (1814-1879) entre otros tratadistas.
Fig. 5. Luigi Manini. Detalle de la logia del Palaço de Buçaco en Coimbra. 1888-1907.

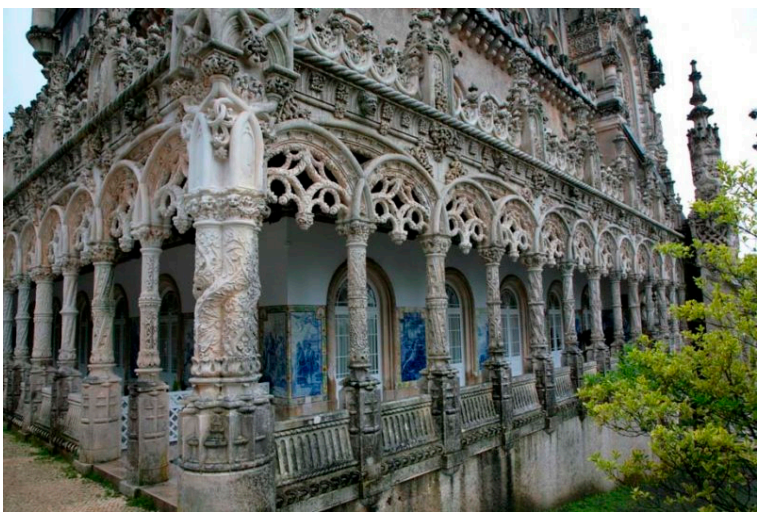

Fig. 6. Juan del Castillo. Detalle del Claustro del Monasterio de los Jerónimos en Lisboa. 1514.

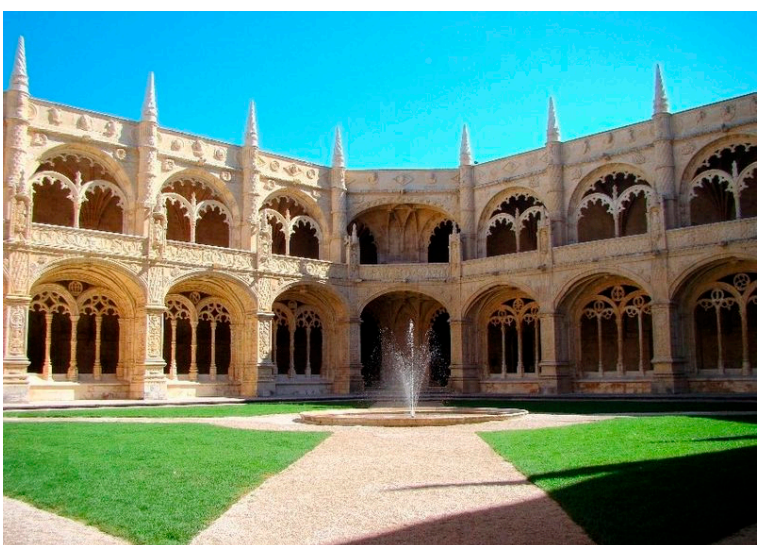

Sin embargo, nuestro primer análisis quedaría incompleto sin el abordaje de un último apunte que creemos fundamental a la hora de valorar las diferentes influencias artísticas de este primer proyecto para el Palacio de la Quinta da Regaleira firmado por el artista cremonese. Debemos partir del hecho de que Manini carecía de formación oficial en el ámbito de la arquitectura, y que su profesión inicial, estaba consagrada por entero al mundo de la escenografía y la pintura. (D' Acie, 1936, p. 14). Incluso, pudiera llegar a argumentarse que su vocación arquitectónica se produjo de una manera un tanto azarosa y aleatoria (Piccarolo, 2005, pp. 272-276). "El paso de la arquitectura a la escenografía fue gradual", por no decir accidentada por una serie de hechos fortuitos que le propiciaron grandes simpatías con la burguesía del momento (Pereira y Luckhurst, 2007 , p. 73, p. 75). De lo que se deduce que, gran parte de su éxito como arquitecto, está "empapado" de su pasado tanto escenográfico como pictórico. Que la arquitectura de Manini sea deudora de sus pretéritas aportaciones escenográficas se antoja una evidencia incuestionable respaldada por grandes especialistas 
como Gaia Piccarolo, Giovanna D’Amia o Cesare Alpini, entre otros. (Piccarolo, 2005, p. 101; D'Amia, 2007, p. 59; Alpini, 2007 , p. 117 , p. 118 , p. 121 , p. 122 , p. 128 ):

\begin{abstract}
"Dicho diálogo -entre la escenografía y la arquitecturava más allá de lo meramente paisajero. No se trata sólo de una influencia implícita -la búsqueda de un genius loci supeditado a la orografía del terreno y la optimización de perspectivas visuales, sino que, ésta, se explicita en los propios proyectos arquitectónicos del artista. De tal modo que, muchas de las obras delineadas, ya estaban esbozadas en precedentes proyectos operísticos y teatrales, al modo de plantillas constructivas" (Moure, 2014, p. 110).
\end{abstract}

El primer proyecto de Manini para el palacio de la Quinta da Regaleira no estará exento de esta fuerte carga escenográfica, dramática y teatral, puesto que "[...] los elementos que componen los edificios [...] son los mismos usados en la arquitectura fantástica que pueblan su escenografía" (Piccarolo, 2005, p. 270).

De igual manera que las escenas para los espectáculos de Bailando Casati (1879) o La favorita (1879) parecen ser el origen bidimensional de posteriores materializaciones tridimensionales como el palacio del Marqués de Foz (1900) y, así como el castillo sobre el mar de Mefístófeles (1880) evoca al Palacio O'Neill (1904) (Piccarolo, 2005, p. 270; Pereira y Luckhurst, 2011, pp. 92-104), el primer proyecto de Manini para la Regaleira parece inspirarse tanto en sus producciones previas para el Tannhäuser (1891-1892) de Richard Wagner (1813-1883) (Carita, 2007, p. 102) como en las escenas del Lohengrin (1873) de su maestro Carlo Ferrario (1833-1907) en los años de trabajo de la Scala de Milán, donde Manini desarrolló su labor profesional durante la década de los 70. [Fig. 7].

Fig. 7. Luigi Manini. Boceto para una escena de Tannhäuser de Richard Wagner. 1891-92. Lisboa. Teatro Sao Carlos. Museo del Teatro/ Luigi Manini.

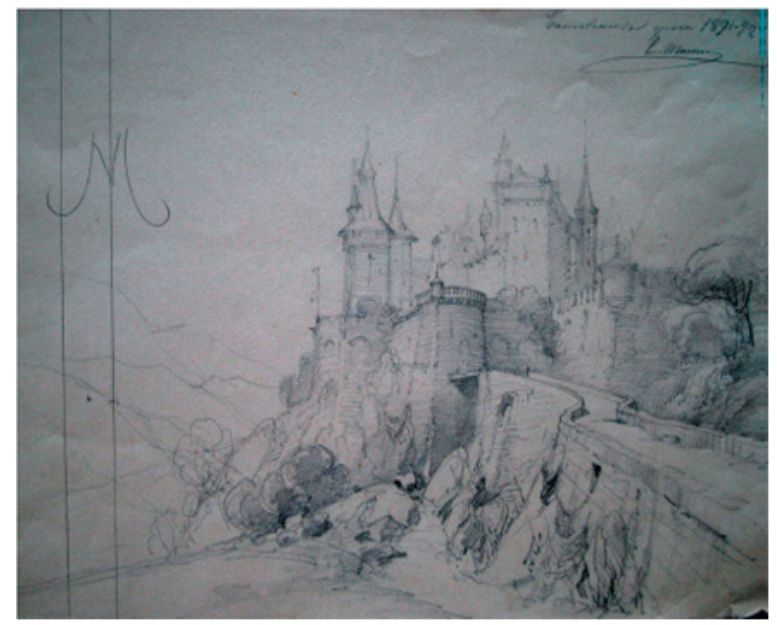

\section{SEGUNDO PROYECTO DE LUIGI MANINI PARA EL PA- LACIO DE LA QUINTA DA REGALEIRA: EL DOMINIO DEL LENGUAJE NEOMANUELINO}

Entre 1898 y 1904, surgen numerosos problemas con la adquisición de los terrenos de la Quinta, frustrando el proyecto inicial de Manini previamente analizado. Esto obliga a Carvalho Monteiro a reconducir su empresa, simplificando las dimensiones de su propuesta y redefiniendo el planteamiento original:

"En este sentido es conocida la intención de António Carvalho Monteiro de ampliar su propiedad con la compra de la Quinta do Relogio que no llega a ser efectuada. Ante esta imposibilidad, António Carvalho Monteiro encomienda un segundo proyecto a Manini tomando como premisa la implantación ya enunciada en el proyecto de Henri Lusseau a partir de las bases del edificio existente" (Carita, 2006, p. 104).

En planta, el nuevo proyecto se alarga, transformando la estructura originaria cuadrangular en rectangular, alterándose, únicamente, en sus líneas de borde y general planteamiento cúbico, por una torre de planta poligonal situada en una de los ángulos del edificio. [Fig. 8]:

"Manini establece un conjunto de alteraciones a la estructura del antiguo edificio procediendo a la apertura de un gran atrio de escaleras que, uniendo varios pisos, acaba por funcionar como gran elemento de articulación y distribución de espacios. La estructura interior se aleja mucho de la claridad y monumentalidad del primer proyecto, hecha de una secuencia de grandes espacios sabiamente articulados con base en dos ejes ortogonales generadores de planta" (Carita, 2006, p. 104).

La reducción estructural, por lo tanto, minimiza las grandes salas del proyecto originario, obligando al arquitecto a la profusión de vanos en los muros de carga con el fin de alcanzar una mayor luminosidad, claridad y oxigenación espacial. Manini gana en verticalidad lo que pierde en horizontalidad. Esto hace que, al haber más pisos, los techos pierdan altura, redundando en la pérdida de diafanidad. También se reduce, en longitud y altura, la monumental galería neomanuelina del piso noble, que Manini, nuevamente, vuelve a compensar con una mayor profusión de vanos desmaterializando la superficie mural. Vanos que, cabe apuntarlo, no solamente actúan como elementos generadores de luz, sino que son, también, los principales motivos ornamentales de las cuatro caras del edificio, recibiendo un tratamiento decorativo diferente en función de la altura y la orientación cardinal.

Otra de las características reseñables del nuevo proyecto, en contraposición al originario, es que el 
ábside pierde cierta independencia estructural integrándose en la ortogonalidad de la planta. Éste se constituirá como el único cuerpo del conjunto ajeno a una estructuración cúbica. También es de notar que la escalera principal se reduce a la "mínima expresión" perdiendo la monumentalidad originaria del gran proyecto principal.

Todo ello confiere al conjunto palacial una mayor verticalidad y liviandad, que acentúa, más si cabe, su deuda neomanuelina. Pináculos, gárgolas, contrafuertes, vidrieras y demás elementos decorativos de clara filiación "gótica" ganan protagonismo, remitiéndonos, inevitablemente, a su precedente proyecto para Buçaco. [Figs. 9-10].

Fig. 8. Luigi Manini. Segundo proyecto para el Palacio de la Quinta da Regaleira: plantas de los tres pisos. 1904. Crema. Museo Cívico de Crema y del Cremasco.

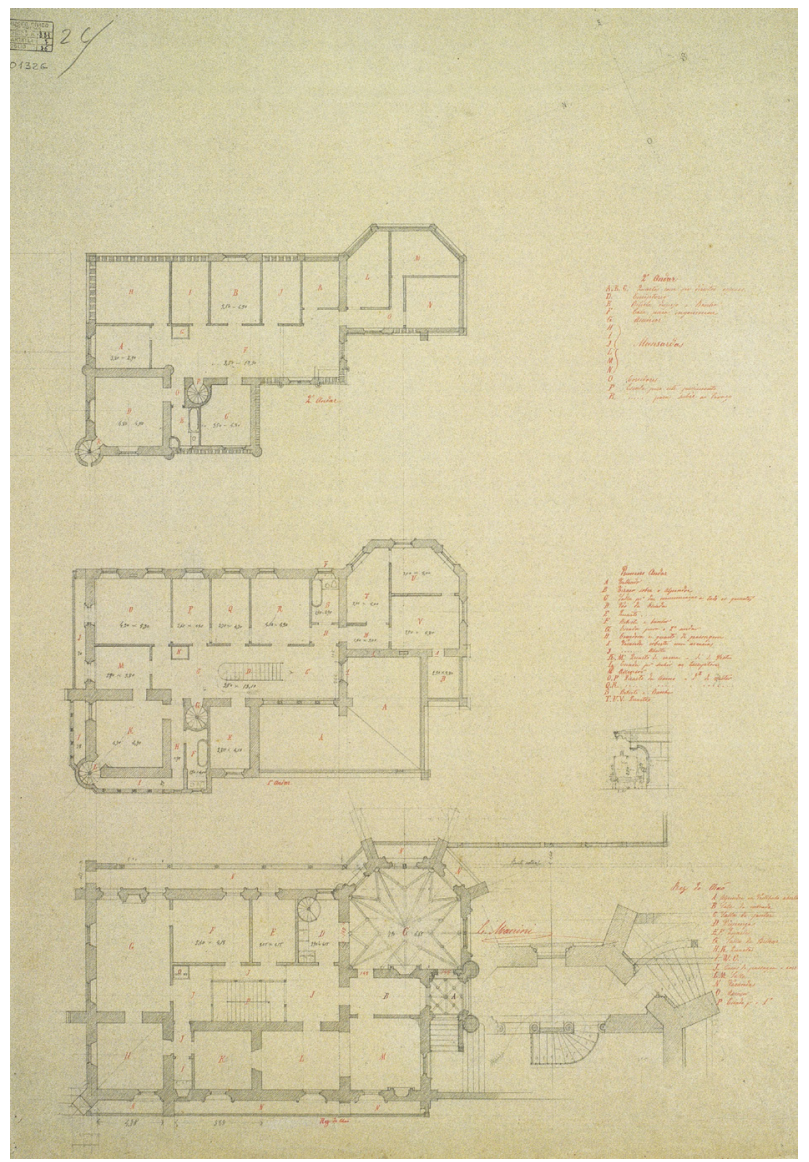

Fig. 9. Luigi Manini. Palacio de la Quinta da Regaleira en Sintra: alzado. 1898-1912.

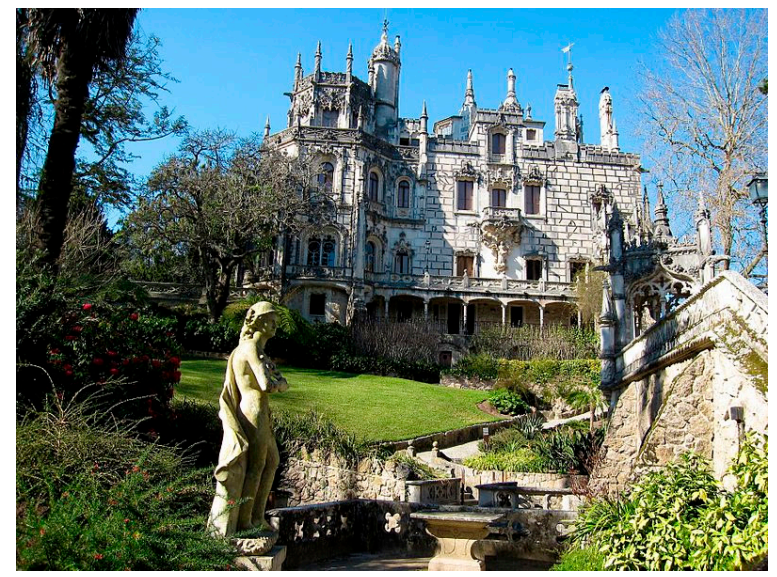

Fig. 10. Luigi Manini. Palaço de Buçaco en Coimbra. 1888-1907.

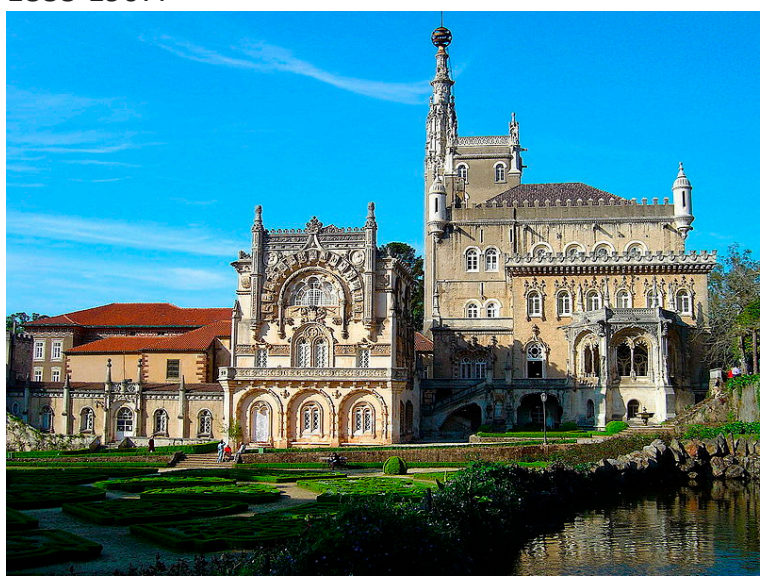

Llegados a este punto, creo que debemos profundizar sobre un tema de suma importancia que merece ser reseñado. Muchas veces se ha incidido sobre la versatilidad del genio cremonese a la hora de interpretar un estilo, el neomanuelino, a priori, ajeno a la cultura arquitectónica italiana, donde, como sabemos, los estilos ortodoxos del flamígero y el gótico bajomedieval fracasaron. Lo cierto es que Manini, pese a haberse formado en Italia, y como bien puede constatarse en su primera obra escenográfica, conocía muy bien el lenguaje arquitectónico del gótico, lo cual pudo contribuir al gran éxito de la aceptación de sus propuestas neomanuelinas tanto en Buçaco como en la Quinta da Regaleira.

No debemos olvidar que entre el 1861 y el 1862, Manini se forma en la Academia de Bellas Artes de Brera en Milán, donde impartía clases Camilo Boito (1836-1914), célebre intelectual romano, cuya propuesta de restauración científica, en su etapa pri- 
mera e inicial, se aproximaba mucho a las doctrinas de estilo de su predecesor Viollet-le-Duc en Francia. Boito había entrado en la Academia como sustituto de Friedrich von Schmidt (1825-1891), quien, en palabras de las especialistas María Dolores Antigüedad y Sagrario Aznar:

"había trabajado en la catedral de Colonia y además había introducido en las enseñanzas de Brera la proyección en estilo gótico. Así Boito recoge una tendencia ya existente marcadamente anticlásica" (Antigüedad y Aznar, 1998, p. 181).

Todo este legado fue plasmado por Boito en su libro Architettura del Medio Evo in Italia, con una introduzione sullo stile futuro dell'architettura italiana (1880), donde se recoge gran parte de sus enseñanzas y teorías tanto profesorales como profesionales. Con atino, la gran especialista Gaia Piccarolo, ha relacionado la obra de Manini con la de Boito, -conjuntamente a otras aportaciones contemporáneas de la tratadística italiana, como el célebre libro de Archimede Sacchi (1837-1886), Le abitazioni: alberghi, case operaie, fabbriche rurali, case civili, palazzi e ville: ricordi compendiati da Archimede Sacchi (1874)- en su magistral artículo "Villa e Villino: il tema dell'abitazione borghese nell'opera di Luigi Manini" (Piccarolo, 2007, p. 99, p. 101, p. 103, p. 105).

Por lo tanto, es muy probable que Manini conociese estos tratados, siendo este hecho demasiado factible para no ser considerado una auténtica certeza. Por consiguiente, debemos afirmar que, ya en su pronta formación artística lombarda, y por su cercanía a Boito, Manini estaba muy familiarizado tanto con el célebre Dictionnaire raisonné de l'architecture française du XIe au XVIe siècle (1854-1868) como con el Dictionnaire raisonné di mobilier française de l'epoque carlovingienne à la Renaissance (1874), del gran teórico francés Viollet-le-Duc. Las copias conservadas de las ilustraciones de sendos libros en Crema bajo puño y letra de Manini parecen asegurar nuestra hipótesis. No debemos olvidar que sendas obras eran, por aquel entonces, fundamentales para el estudio del neogótico. Manini, a no dudar, tomó de ellas inspiración para la realización de sus producciones neohistoricistas tanto escenográficas como arquitectónicas de corte neomedieval:

\footnotetext{
"Las cuerdas y los nudos de las cornisas, las esferas armilares, las cruces, [...] reflejan el conocimiento de la orfebrería contemporánea y pasada, donde las ornamentaciones románicas, moriscas, y orientales se insertan sobre una estructura gótica" (Cordera, 2007, p. 113).
}

Otra de la pruebas irrefutables de que Manini, pese a su origen lombardo, se encontraba empapado de cultura bajo medieval, lo encontramos ya en la temprana figura de Domenico Moglia, célebre arquitecto fundador de la cátedra de ornamento de la Academia de Bellas Artes de Brera donde Manini se formó (Letterari, 1821, p. 283). Domenico Moglia, escribió, para sus alumnos de la academia, un libro fundamental titulado Collezione di soggetti ornamentali ed architettonici inventati e disegnati da Domenico Moglia (1837) (Ricci, 1997, p. 64; Ricci, 2007a, p. 17)². En las páginas finales del tratado -precediendo incluso a los estudios de Viollet-leDuc- se lleva a cabo un análisis de una iglesia gótica, poniéndose de manifiesto la importancia del estudio de la arquitectura medieval en la Italia del S. XIX, así como la pertinencia de su análisis, en un territorio, a priori, ajeno a toda influencia gótica (Moglia, 1837, pp. 121-124). [Figs. 11-13]. Por otra parte, el vínculo Domenico Moglia y Luigi Manini, no debiera extrañarnos en absoluto, pues, ya en el año 2007, Luciano Roncai en su artículo "Giardini e Ville tra ottocento e novecento nel cremonese", establece vínculos claros entre las obras del autor de la Quinta da Regaleira y la obra de Luigi Voghera -primo de Domenico Moglia-, autor de numerosas obras de corte neorromántico en territorio lombardo (Roncai, 2007, pp. 39-47).

Por lo tanto, es muy probable que toda esta rápida absorción del lenguaje gótico y por extensión neomanuelino, se debiera, en gran medida, a su formación inicial, paradójicamente, italiana. Tampoco estaría de más apuntar que la región lombarda, quizás por su situación fronteriza con Europa central, sea el territorio de la península itálica donde el neogótico permeó con más fuerza e intensidad, favoreciendo, en consecuencia, grandes construcciones de influjo romántico y neomedieval en la época de formación del artista cremonese. Con razón apostilla Giuliana Ricci: “La Lombardía se afirma, por lo tanto, también en el ámbito artístico, en su papel de vínculo entre Europa e Italia" (Ricci, 2007a, p. 27). La Catedral de Milán (1386-1805), única en suelo italiano, sigue siendo un magnífico ejemplo de esta tradición y permeabilidad gótica en la Lombardía [Fig. 14]. No es baladí, que en el libro fotográfico de Manini titulado Albúm collections (1936), -conservado en el Museo Cívico de Crema y del Cremasco- la catedral de Milán sea uno de los monumentos propuestos a análisis por el autor (Cassanelli, 2007, p. 134). 
Figs. 11-13. Domenico Moglia. Detalles del libro Collezione di soggetti ornamentali ed architettonici inventati e disegnati da Domenico Moglia. 1837.
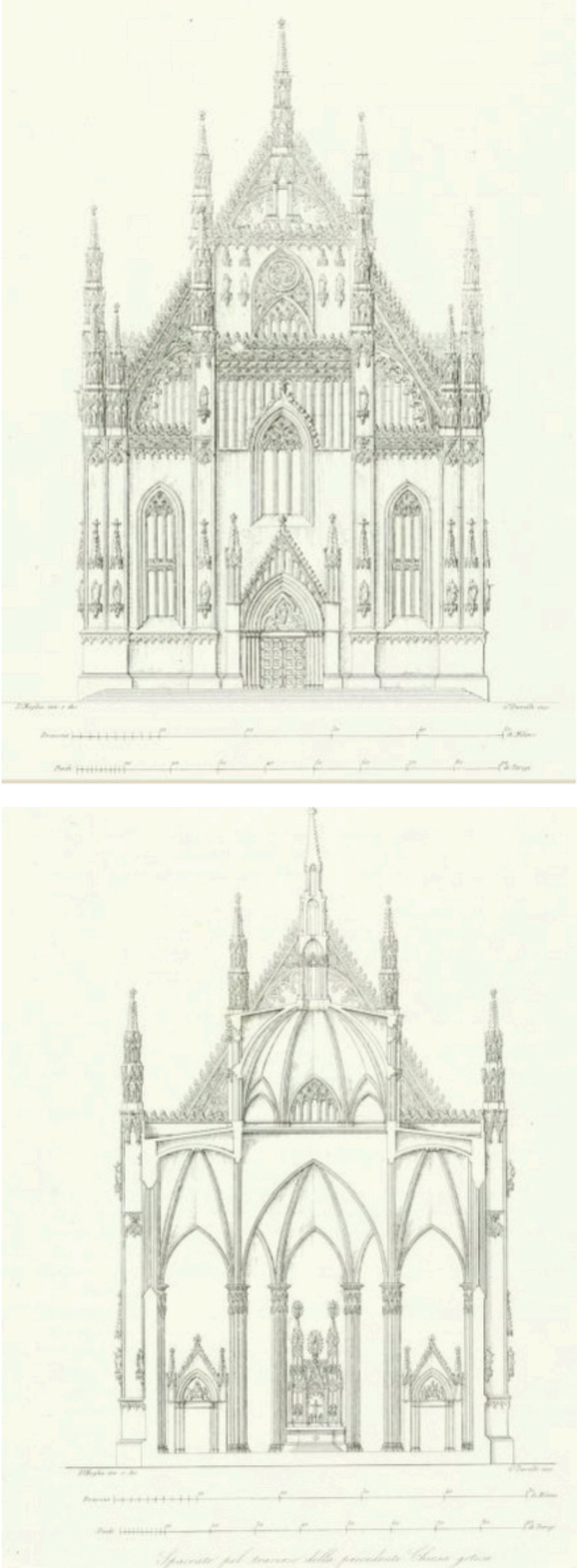

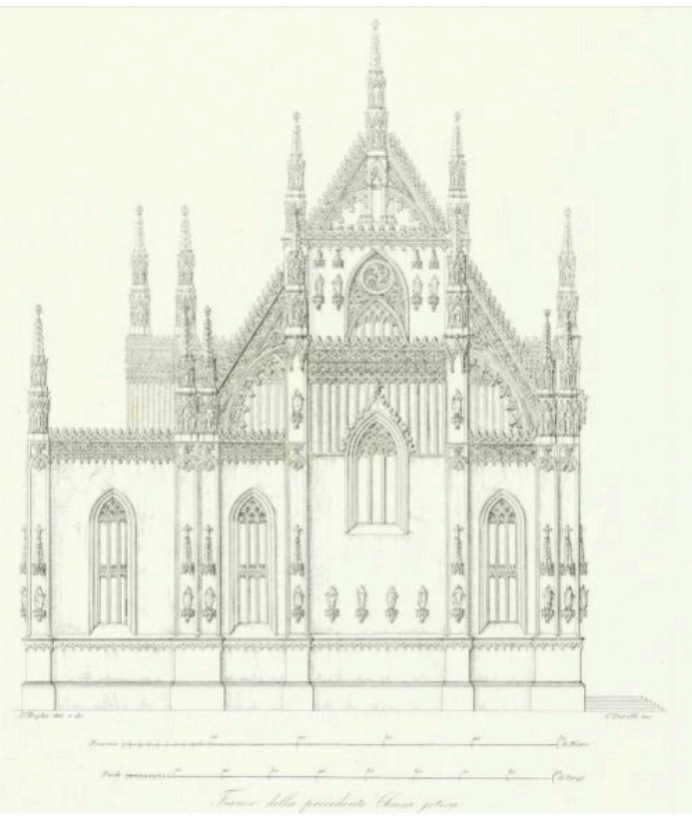

Fig. 14. Simone da Orsenigo, Nicolas de Bonaventure, Pellegrino Tibaldi y Carlo Pellicani Junior. Catedral de Milán. 1386-1805.

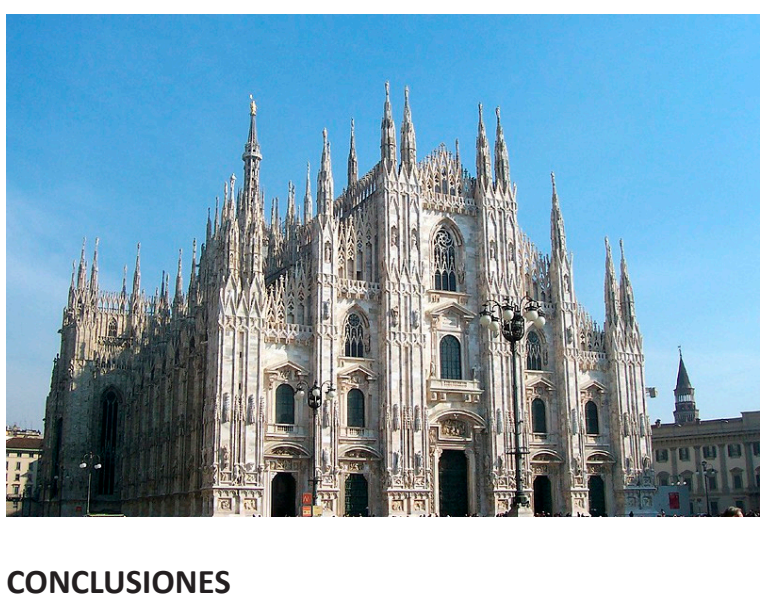

Dábamos comienzo a este artículo planteando una serie de cuestiones iniciales relativas al proceso constructivo y configurador de la actual Quinta da Regaleira con motivo del octogésimo aniversario de la muerte de su hacedor. Muchos fueron los elementos facilitadores y condicionantes que redundaron en la creación de la actual e imponente obra. La falta de entendimiento previo entre Monteiro y Lusseau en cuanto a la primera propuesta proyectiva del complejo facilitó el acercamiento de Manini. De todas formas, mantenemos que la relación artística entre el filántropo brasileiro y el arquitecto francés, estuvo condicionada y supeditada a la incompatibilidad personal, remarcada por sus fuertes personalidades. Que la propuesta de 
Lusseau obedecía a un gusto académico típicamente francés es un hecho, que dicha propuesta fuera realizada sin consentimiento previo de Monteiro, parece, cuanto menos, dudoso. Afirmar que Lusseau presentó dicha propuesta sin el beneplácito previo de Monteiro resulta poco factible. De todos modos, no existe documentación esclarecedora sobre dicha correspondencia, dirimiendo, irremediablemente, en el "pantano" de la conjetura. Lo que sí puede afirmarse, con total certeza, es que la presentación del proyecto de Lusseau, no se produjo por una limitación de sus recursos artísticos. Prueba incuestionable de su versatilidad artística la encontramos en el proyecto neomorisco presentado por Lusseau al rico industrial Conceição e Silva en Lisboa. Todo esto, parece hablar en favor de su enorme destreza a la hora de interpretar los diferentes estilos neohistoricistas del momento.

Cuando entra en escena Manini, Monteiro parece tener más concretizadas sus querencias artísticas. El artista cremonese despliega toda su cultura escenográfica avalada arquitectónicamente por el magnífico logro de Buçaco, cuyo proceso constructivo se solapa con el de la Quinta da Regaleira, llegando, incluso, a retroalimentarse. En este primer proyecto, se acusa una fuerte deuda escenográfica, ejemplificándose lo que Giovanna D’Amia ha denominado como "espacialidad amplificada" (D'Amia, 2007, p. 56), consistente en convertir la imagen bidimensional en real tridimensionalidad; es decir, el paso imaginístico de la pintura escenográfica a la verdadera espacialidad arquitectónica. La carencia de una formación académica oficializada, pese a contar con una nutridísima cultura arquitectónica autodidacta, juega a su favor, imprimiendo a esta disciplina un fuerte carácter escenográfico:

"La práctica de la pintura decorativa, una extensión de la dramaturgia, le condujo a la comprensión plástica de los estilos llamados históricos, que aplicó con extrema habilidad a las artes decorativas y a la arquitectura [...]" (Pereira y Luckhurst, 2006, p. 77) -y en otro texto-"La capacidad de inventar la escena era casi exclusiva del escenógrafo titular y no sólo del escenógrafo pintor al que nos referimos. En Portugal, por circunstancias coyunturales económicas, y por la resistencia del público a la introducción del naturalismo y el realismo en la escena nacional, la oportunidad de Manini de ejercitar esta cualidad de inventor de escenas en los espectáculos fue poco frecuente. En este sentido, en Sintra, se impone como arquitecto y paisajista, con innegable capacidad y creatividad" (Luckhurst y Pereira 2007, p. 96).
Este diálogo entre el Manini arquitecto y escenógrafo, alcanza su cénit en el primer proyecto para la Quinta da Regaleira, donde dicho diálogo no sólo se establece a un nivel implícito sino también explícito, tal y como hemos constatado en el segundo epígrafe de esta investigación. Que el primer proyecto de Manini para la Quinta sintrense, sea deudor de su producciones previas para las diferentes óperas wagnerianas, -firmadas por él mismo o por su maestro Carlo Ferrario-, se antoja una evidencia incuestionable.

Cuando surjan los primeros problemas con la adquisición de los terrenos, Manini se ve obligado a redimensionar su proyecto, convirtiéndolo, andando el tiempo, en la obra más representativa del neomanuelino portugués. Para ello, Manini echa mano de su extensa cultura autodidacta, conjugada con su enorme formación escenográfica como dibujante de paisajes y arquitecturas. Podríamos afirmar que Manini "empezó la casa por el tejado", aprendiendo primero a proyectar arquitecturas sirviéndose del poco arriesgado ejercicio del dibujo, para más tarde, someterse al cálculo arquitectónico, indispensable, por otra parte, para domeñar las estrictas y peligrosas leyes gravitatorias. Ni que decir tiene que este último apunte no es baladí, pues, en los tiempos en los que Manini desarrolla este primer proyecto, todavía sobrevolaba la tragedia del derrumbamiento de la torre del Monasterio de los Jerónimos de 1878, acaecida durante la restauración de Giuseppe Cimatti (1808-1879) y Achille Rambois (1810-1880) -dos compatriotas y amigos de Manini-, causando la muerte de 10 operarios (D’Amia, 2007 p. 57).

En este contexto vienen a colación los grandes "popes" de la tratadística bajo medieval, que Manini copia y estudia con ahínco. Domenico Moglia, VioIlet-le-Duc, Archimede Sacchi, Friedrich von Schmidt, y Camilo Boito, aportan las soluciones constructivas definitivas para el levantamiento de sus grandes edificios neomanuelinos. Paradójicamente, dicho neomanuelino, había encontrado su mayor valedor en un artista lombardo, previamente formado en la cultura bajo medieval de la península itálica. Luigi Manini, en el octogésimo aniversario de su muerte, es principalmente reseñado por sus contribuciones al neomanuelino, más que por cualquier otra aportación artística. Sin embargo, el haberse convertido en un apátrida no jugó en su favor. Su continuo nomadismo entre Italia y Portugal dificultó, en cierta manera, la difusión e internacionalización de su obra entre los años 30 y 90 del pasado siglo: 
“Aparte de pocos períodos en su vida (la infancia y la primera adolescencia). Manini parece una persona habituada a la soledad, persona que observa y medita apartada. ¿Quién lo ha conducido a la aventura portuguesa? ¿Quién lo ha acompañado en el periplo iconológico? [...] Manini no es, ciertamente, un hombre de brillantes relaciones públicas. Ninguna academia lo destaca entre sus socios de arte, ni en Italia ni en Portugal; ninguna exposición internacional italiana quiere hacerse cargo de la obra de un ciudadano como él que se ha establecido en el extranjero" (Ricci, 2007b, p. 15).

\section{AGRADECIMIENTOS}

El presente artículo forma parte del proyecto internacional Laboratorio di Ricerca sulle Città (Istituto di Studi Superiori. Università di Bologna). Asimismo, también del proyecto europeo Performigrations: people are the territory (Dipartimento di Lingue, Letterature e Culture Moderne. Università di Bologna). Análogamente, dicha ponencia ha sido posible gracias a la financiación postdoctoral del Plan Galego de Investigación, Innovación e Crecemento 2011-2015 promovido por la Xunta de Galicia.

\section{NOTAS}

1. Toda la bibliografía del presente artículo se encuentra editada únicamente en italiano y portugués. Todos los textos citados han sido traducidos por el autor al castellano.

\section{BIBLIOGRAFÍA}

Alpini, C. (2007). Manini Pittore. En Piccarolo, G. e Ricci, G. (coords.). Catálogo de la exposición: Luigi Manini (1848-1936) architetto e scenografo pittore e fotografo (Crema, Citadellla della Cultura, 6 maggio-8 luglio, 2007). Milano: SilvanaEditoriale, pp. 117-129.

Antigüedad, M. D. y Aznar, S. (1998). El Siglo XIX. El cauce de la memoria. Madrid: Istmo.

Boito, C. (1880). Architettura del Medio Evo in Italia, con una introduzione sullo stile futuro dell'architettura italiana, Milano: Hoepli.

D’Acie (Pseudónimo de Augusto Cambiè) (1936). Luigi Manini scenografo-architetto, Crema: tipografía la Moderna.

Carita, H. (2006). A Quinta da Regaleira: Projecto e Método. En Cruz Alves, J. (coord). Cátalogo de la exposición: Luigi Manini: Imaginário y Método, Arquitectura y Cenografia (Sintra, 29 de Junho-31 de outubro, 2006). Sintra: CulturSintra, pp. 90-98.

Cassanelli, R. (2007). Nel laboratorio del fotografo. Luigi Manini e gli usi della fotografia. En Piccarolo, G. e Ricci, G. (coords.). Catálogo de la exposición: Luigi Manini (1848-1936) architetto e scenografo pittore e fotografo (Crema, Citadellla della Cultura, 6 maggio-8 luglio, 2007). Milano: SilvanaEditoriale, pp. 131-139.

Cordera, P. (2007). II mestiere dell'arte. Luigi Manini e la reinterpretazione
2. El Getty Research Institute cuenta con un fabuloso ejemplar de difícil consulta, incluso, en archivos italianos.

del passato tra architettura e arti decorative. En Piccarolo, G. e Ricci G. (coords.). Catálogo de la exposición: Luigi Manini (1848-1936) architetto e scenografo pittore e fotografo (Crema, Citadellla della Cultura, 6 maggio-8 luglio, 2007). Milano: SilvanaEditoriale, pp. 109-115.

D’Amia, G. (2007). Luigi Manini scenografo. Dalla formazione scaligera ai trionfi portoghesi. En Piccarolo, G. e Ricci, G. (coords.), Catálogo de la exposición: Luigi Manini (1848-1936) architetto e scenografo pittore e fotografo (Crema, Citadellla della Cultura, 6 maggio-8 luglio, 2007). Milano: SilvanaEditoriale, pp. 53-65.

Denby, E. (1998). Grand Hotels: Reality and Illusion; an architectural and Social History, London: Reaktion Books.

França, J.-A. (1998). A Arte en Portugal no século XIX, Lisboa: Bertrand editora.

Letterari, Da V. (1821). Giornale de letteratura, scienze ed arti. Milano: Imperiale regia stamperia.

Luckhurst, G. y Pereira, D. (2004). Luigi Manini no Buçaco. En Monumentos, 20, pp. 51-63.

Luckhurst, G. y Pereira, D. (2006). Carvalho Monteiro: mecenas e coleccionador. En Cruz Alves, J. (coord.), Cátalogo de la exposición: Luigi Manini: Imaginário y Método, Arquitectura y Cenografia (Sintra, 29 de Junho-31 de outubro, 2006). Sintra: CulturSintra, pp. 90-98.
Luckhurst, G. y Pereira, D. (2007). Dalla poetica della natura alla costruzione del paesaggio e del giardino. L'interpretazione di Luigi Manini. En Piccarolo, G. e Ricci, G. (coords.). Catálogo de la exposición: Luigi Manini (18481936) architetto e scenografo pittore $e$ fotografo (Crema, Citadellla della Cultura, 6 maggio-8 luglio, 2007). Milano: SilvanaEditoriale, pp. 87-99.

Manini, L. (1936). Album de collections. Fotografie di monumenti vari e fotografie famigliari de Luigi Manini. (Inédito).

Moglia, D. (1837). Collezione di soggetti ornamentali ed architettonici inventati e disegnati da Domenico Moglia, Milano: Tip. Dottore G. Ferrario.

Moure, I. (2011). El Gran Proyecto de Antonio Bermejo y Arteaga para Santiago de Compostela: la Escuela de Veterinaria como émula de la École d'Anatomie d'Alfort en París. Cuadernos de Estudios Gallegos, 124, pp. 253-274.

Moure, I. (2014). Las Villas de Luigi Manini en Sintra (1890-1912). Ángulo Recto. Revista de estudios sobre la ciudad como espacio plural, VI, 2, pp. 101-116.

Pereira, D. y Luckhurst, G. (2004). A Vila Sassetti, projecto do cenógrafo-arquitecto Luigi Manini. Varia Escrita, 11, pp. 253-280.

Pereira, D. y Luckhurst, G. (2006). Entre Sintra e Cascais. En Cruz Alves, J. (coord.). Catálogo de la exposición: Luigi Manini: Imaginário y Método, 
Arquitectura y Cenografia (Sintra, 29 de Junho-31 de outubro, 2006). Sintra: CulturSintra, pp. 77-89.

Pereira, D. y Luckhurst, G. (2008). Luigi Manini e o projecto da Vila Sassetti. Monumentos, 26, pp. 200-210.

Pereira, D. y Luckhurst, G. (2011). O programa estético da casa de Jorge O'Neill, a partir dos contributos de Luigi Manini, Francisco Vilaça e Albrecht Haupt. Monumentos, 31, pp. 92-105.

Pereira, D. (2012). A cenografia oitocentista como fonte de cultura visual e de ideologia. História da arte, 10, pp. 147-159.

Piccarolo, G. (2005). Luigi Manini (18481936). L'opera architettonica di uno scenografo italiano in Portogallo. [Tesis de Licenciatura inédita]. Politécnico de Milano: Milano.

Piccarolo, G. (2007). Villa e Villino: il tema dell'abitazione borghese nell'opera $d$ Luigi Manini. En Piccarolo, G. e Ricci, G. (coords.). Catálogo de la exposición:
Luigi Manini (1848-1936) architetto e scenografo pittore e fotografo (Crema, Citadellla della Cultura, 6 maggio-8 luglio, 2007). Milano: SilvanaEditoriale, pp. 99-107.

Ricci, G. (1997). Architettura in fiore. En Pavoni, R. (ed.). The reviving the renaissance. The use and abuse of the past in nineteenth-century Italian art and decoration. Cambridge: Cambridge University Press.

Ricci, G. (2007a). L'archittetura come arte applicata per il benessere del popolo e della nazione. En Piccarolo, G. e Ricci, G. (coord.). Catálogo de la exposición: Luigi Manini (1848-1936) architetto e scenografo pittore e fotografo (Crema, Citadellla della Cultura, 6 maggio-8 luglio, 2007). Milano: SilvanaEditoriale, pp. 17-27.

Ricci, G. (2007b). Introduzione. En Piccarolo, G. e Ricci, G. (coords.). Catálogo de la exposición: Luigi Manini (1848-1936) architetto e scenografo pittore e foto- grafo (Crema, Citadellla della Cultura, 6 maggio-8 luglio, 2007). Milano: SilvanaEditoriale, pp. 14-15.

Roncai, L. (2007). Giardini e ville tra ottocento e novecento nel cremonese. En Piccarolo, G. e Ricci, G. (coords.). Catálogo de la exposición: Luigi Manini (18481936) architetto e scenografo pittore $e$ fotografo (Crema, Citadellla della Cultura, 6 maggio-8 luglio, 2007). Milano: SilvanaEditoriale, pp. 39-47.

Sacchi, A. (1874). Le abitazioni: alberghi, case operaie, fabbriche rurali, case civili, palazzi e ville: ricordi compendiati da Archimede Sacchi. Milano: Hoepli.

Viollet-le-Duc, E. (1868). Dictionnaire raisonné de l'architecture française du $X I^{\circ}$ au XVI siècle (1854-1868). Paris: Édition BANCE - MOREL.

Viollet-le-Duc, E. (1874). Dictionnaire raisonné di mobilier française de l'époque carlovingienne à la Renaissance. Paris: Édition BANCE - MOREL. 